\title{
Effect of thermal treatment on morphological properties of borosilicates glass doped with silver
}

\author{
Dores D. R. S. ${ }^{* 1}$, Souza L. C. ${ }^{3}$, Giehl J. M. ${ }^{2}$, Ludwig V. ${ }^{1}$, Silva V. R. ${ }^{1}$, Oliveira V. H. ${ }^{1}$, \\ Costa R. C. ${ }^{4}$, Pacheco T. S. ${ }^{1}$, Rodrigues C. L. V. ${ }^{1}$, Pinotti C. N. ${ }^{1}$, Costa Z. M. ${ }^{1}$ \\ 1 - Federal University of Juiz de Fora, Department of Physics, Juiz de fora, MG, Braizil \\ 2 - University of São Paulo, Institute of Physics of São Paulo, SP, Brazil \\ 3 - University of Brasília, Institute of Physics, Brazil \\ 4 - Polytechnic Institute of Millano, Itália \\ *e-mail: diogo_rsd@yahoo.com.br
}

\begin{abstract}
Glasses containing metallic nanoparticles are promising materials that should also possess the best spectroscopic, chemical, mechanical and thermal characteristics for technological applications in optics and photonics. For this reason it was chosen to synthesize and characterize the pure silver doped borosilicate glasses and silver nitrate. The present work investigates the generation of silver nanoparticles on the surface and the mass of a borosilicate glass in which it was directed to the synthesis process in which it was consisted: in the stoichiometric calculations, in the determination of the melting temperature, in the choice of reagents with high degree of purity, in the manufacture of the samples, in the appropriate polishes and in the determination of heat treatments close to $\mathrm{Tg}$ of the glass in question. From this phase, the research followed the application of techniques of differential thermal analysis (ATD) and transmission electron microscopy (MET). Thus, from the results and analyzes obtained, it was possible to observe that the borosilicate glass samples of this work will obtain satisfactory experimental results, in which it was possible to prove its optical and structural properties similar to those recognized in literature, thus making it a promising material in area of vitreous materials applied to nanotechnology borosilicate glasses are obtained from the combination of silicon dioxide $\left(\mathrm{SiO}_{2}\right)$ with boron oxide $\left(\mathrm{B}_{2} \mathrm{O}_{3}\right)$ and the resulting samples were annealed at various temperatures. Due to the structural shape, these glasses have a high resistance to thermal shock, good chemical durability and excellent electrical resistivity compared to other glasses on the market today. Therefore, based on these important structural, physical and chemical characteristics and also in the variety of applications, this study was chosen for the synthesis and characterization of pure borosilicate glass and doped with silver nitrate. We verified the formation of silver nanoparticles, after the heat treatment, by transmission electron microscopy.
\end{abstract}

Keywords: borosilicate glasses, silver nanoparticles, transmission electron microscopy (TEM).

\section{Introduction}

One of the main interests in metallic nanoparticles arises from the local field enhancement effect that has been used for a great number of applications, from sensors to nonlinear optics [1, 2, 3, 4]. The light absorption by nanoparticles produces a coherent and collective oscillation of the electrons, contributing to the enhancement of linear and nonlinear optical properties [1]. These properties are influenced not only by the size and the shape of the nanoparticles but also by the dielectric environment of the host material [5]. Glasses containing metallic nanoparticles are promising materials for photonic applications because they exhibit ultrafast response times and high third order nonlinearities $[6,7,8,9]$.
Glasses containing boron oxide $\left(\mathrm{B}_{2} \mathrm{O}_{3}\right)$ are obtained by the dehydration of the boric acid (H3BO3) above a temperature of between $260{ }^{\circ} \mathrm{C}$ and $270{ }^{\circ} \mathrm{C}$ at a reduced pressure in the range of 130 to $260 \mathrm{~Pa}$. In a glass made of pure boron oxide, the basic structures are formed exclusively by $\mathrm{BO} 3$ triangles so the oxygens of the structure form bridges between the two boron atoms. These units are constituted of planar triangles of $\mathrm{B}_{2} \mathrm{O}_{3}$ where each $\mathrm{B}_{2} \mathrm{O}_{3}$ triangle is connected to the other by bridging oxygens forming a plan hexagonal ring, like the boroxol ring. The oxygen bridge between two cations of either $\mathrm{B}$ or $\mathrm{Si}$ is a strong bond that helps hold the amorphous network togheter $[10,11]$. The schematic representation of the structure 
of network formers and network modifier in borosilicate glass is shown in Figure 1.

\section{$\lambda$}

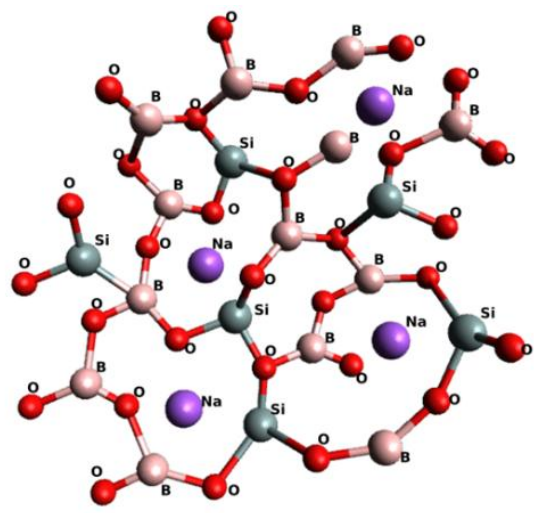

Figure 1: Schematic representation of the structure of network formers and network modifier in borosilicate glass, using the Avogadro $3 \mathrm{~d}$ molecular editor.

This paper presents a study on the generation and the interactions of silver nanoparticles in the

host matrix $(40-x) \mathrm{B}_{2} \mathrm{O}_{3}(30-x) \mathrm{SiO}_{2}(2-x) \mathrm{Al}_{2} \mathrm{O}_{3}(23-x) \mathrm{Na}_{2} \mathrm{O}(5$ $-\mathrm{x}) \mathrm{ZnO}_{2}$ where $\mathrm{x}=0.25 \mathrm{~mol} \% \mathrm{AgNO} 3$ prepared from high purity raw materials. The effect of annealing temperature on optical and structural properties of synthesized Ag-glass nanocomposite has been investigated in detail. The presence of the nanoparticles was confirmed by transmission electron microscopy.

\section{Methodology}

The samples were prepared by using conventional melting- quenching technique with a mixture of the constituent oxides heated in an electrical furnace at a temperature around $1450^{\circ} \mathrm{C}$ for four hours under normal atmospheric conditions and then quenched onto a stainless-steel plate. Better homogeneity of the melt was achieved by removing the crucible from the de furnace and swirling several times. $\mathrm{SiO}_{2}, \mathrm{Al}_{2} \mathrm{O} 3, \mathrm{~B}_{2} \mathrm{O}_{3}$ oxides (Aldrich Chemical Company having 99,99\% percent purity level) were used as starting materials, as it can be seen in Table 1.

Table 1: Molar composition (mol\%) of samples prepared in this study: BSP (glass no dopped) BSDAg (glass doped with silver).

\begin{tabular}{c|c|c|c|c|c|c} 
Sample & $\begin{array}{c}\mathrm{B}_{2} \mathrm{O}_{3} \\
(\mathrm{Mol} \%)\end{array}$ & $\begin{array}{c}\mathrm{SiO}_{2} \\
(\mathrm{Mol} \%)\end{array}$ & $\begin{array}{c}\mathrm{Al}_{2} \mathrm{O}_{3} \\
(\mathrm{Mol} \%)\end{array}$ & $\begin{array}{c}\mathrm{Na}_{2} \mathrm{O} \\
(\mathrm{Mol} \%)\end{array}$ & $\begin{array}{c}\mathrm{ZnO} \\
(\mathrm{Mol} \%)\end{array}$ & $\begin{array}{c}\mathrm{AgNO}_{3} \\
(\mathrm{Mol} \%)\end{array}$ \\
\hline BSP & 40,00 & 30,00 & 2,00 & 23,00 & 5,00 & - \\
\hline BSDAg & 39,90 & 29,93 & 1,99 & 22,94 & 4,99 & 0,25 \\
\hline
\end{tabular}

Glass transition temperature $(\mathrm{Tg})$ was determined by Differential Scanning Calorimetry (DSC), using a Shimadzu DTA-50 instrument, in platinum pans, within a range of $20{ }^{\circ} \mathrm{C}$ to $900{ }^{\circ} \mathrm{C}$ with a heating rate of $10{ }^{\circ} \mathrm{C} / \mathrm{min}$, and in a synthetic air atmosphere. From DSC curve was obtained Tg value of the $496{ }^{\circ} \mathrm{C} \pm 2{ }^{0} \mathrm{C}$ and no exothermic peak was found, indicating that there is no formation of crystalline phases during the heating up to $700{ }^{0} \mathrm{C}$.The Transmission Electron Microscopy (TEM) and Energy Dispersive X-ray Spectroscopy (EDX) analysis were accomplished using a Philips CM 200 Microscope operating at a $200 \mathrm{kV}$. For this study, samples were prepared in the following way: a diamond scriber was utilized to scratch the surface (a few microns below) of the glass containing silver nanoparticles. The samples selected for TEM were scraped surface and diluted in water, where only the particles that remained on the surface of the solution were placed in a micro-screen with previously deposited carbon. Consequently, the larger glass particles settled down and the finer ones floated on the surface of the liquid. The finest layer on the surface was collected on the carbon coated copper grid for observation $[12,13]$. To obtain the size and size distributiondata was used a free program for particle counting named image $\mathrm{J}[14,15]$.

\section{Discussion and Results}

Temperatures are identified by $\mathrm{T}_{\mathrm{g}}$ (glass transition temperature), $\mathrm{T}_{\mathrm{x}}$ (crystallization onset temperature), Tm (melting temperature) and $\mathrm{K}_{\mathrm{H}}$ (Hruby parameter). These temperatures were determined graphically by the intersection of tangents to the baseline and the slope of the curve. The dates are shown in Figure 2 shows the thermogram where the BSP powder samples. where $\mathrm{Tg}$ : glass transition temperature $\left(496{ }^{\circ} \mathrm{C}\right)$; $\mathrm{Tx}$ : crystallization temperature $\left(559{ }^{\circ} \mathrm{C}\right)$; Tf: melting temperature $\left(684{ }^{\circ} \mathrm{C}\right)$ and $\mathrm{K}_{\mathrm{H}}$ : Hrubry parameter (0.39).

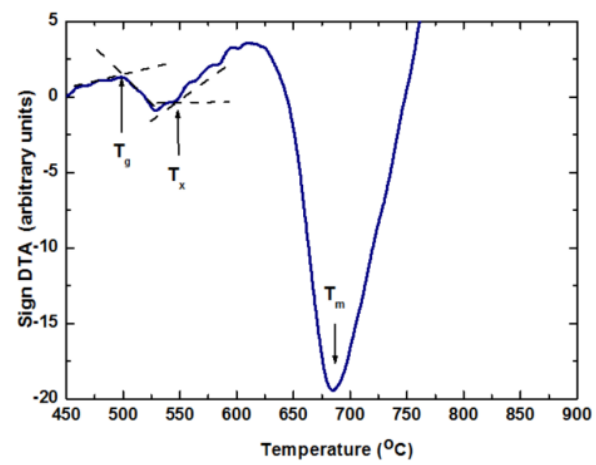

Figure 2: Thermogram for the pure borosilicate glass sample without heat treatment BSP sample. Tg: glass transition temperature; Tx: crystallization temperature; Tm: melting temperature.

It is known from the literature that the thermal stability can be evaluated by the entity difference of temperatures $\mathrm{Tx}-\mathrm{Tg}$, where values above $100{ }^{\circ} \mathrm{C}$ indicates a good thermal stability of the glass. The glass used in this study was pure borosilicate, the value found for this difference was $53{ }^{\circ} \mathrm{C}$. It is possible to conclude that thermal stability of the glass is not very good. But on the other hand, the Hruby parameter shows that the behavior of the vitreous network of the BSP has a parameter which is between $0.1<\mathrm{K}_{\mathrm{H}}<0.5$ 
do not exhibit crystallization, and which may be easily manufactured. It was decided to analyze by TEM technique only samples having obtained the best optical absorption spectrum, so it was chosen by B3 samples (treated at $300{ }^{\circ} \mathrm{C}$ for one hour) and B5 (treated by $400{ }^{0} \mathrm{C}$ for one hour) with the aim of studying the types of changes that the heat treatment causes the vitreous samples and the formation of nanoparticles that are part of this internal structure. The Tables 6 lists the parameter used for obtaining the EDX spectra of the samples B3 and B5 respectively [16].
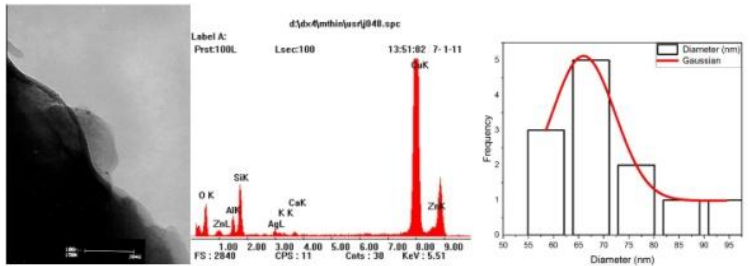

Figure 3: (a) Results of TEM micrographs and (b) EDX of borosilicate glass sample doped with silvernitrate and heat treated at $300{ }^{\circ} \mathrm{C}$ for one hour (B3). Showing distinct regions: (A) B3. (c) Correspondingsize distribution with Gaussian curve fit.

Table 2: Parameters used for obtaining the EDX spectra of the sample B3 and B5.

\begin{tabular}{c|c|c|c|c} 
EDX & FS & CPS & Cnts & KeV \\
\hline \multirow{3}{*}{ B3 } & 2840 & 11 & 30 & 5.51 \\
\cline { 2 - 5 } & 2851 & 6 & 32 & 5.51 \\
& 3409 & 8 & 32 & 5.51 \\
\hline \multirow{3}{*}{ B5 } & 4370 & 7 & 49 & 5.51 \\
& & 5 & 30 & 5.51 \\
& 3479 & 7 & 46 & 5.51 \\
\hline
\end{tabular}

The Figures 3, 4, 5 and 6 show the effect of annealing on the $\mathrm{Ag}$ dispersion in the glass matrix. As can be seen in these figures nanoparticles are condensed into small agglomerates. In Figures 4, 5 and 6 can observe the three micrographs with their respective spectra EDX (sample B3), where it is possible to see the silver nanoparticles with diameters ranging from 10 to $100 \mathrm{~nm}$, which in the picture correspond to black spherical dots indicated by arrows. Observing these figures was observed the presence of few silver nanoparticles dispersed among themselves and the presence of silver nanoparticles, which are closer to each other. This increase in the number of nanoparticles due to the heat treatment of the samples. Figure 6 shows an abundant presence of silver nanoparticles, even when compared with the other samples, where it was possible to obtain the isolated nanoparticles, since some are dispersed and correspond to the black spherical dots, while in the other samples there are four small clusters distributed on the surface. Observing the EDX spectra is remarkable the presence of CuK peak that belongs to the copper-sample holder used for performing the measurement. For all EDX spectrum is always observed the presence of $\mathrm{Ag}, \mathrm{Al}, \mathrm{Zn}, \mathrm{Si}, \mathrm{Ca}, \mathrm{O}$ and $\mathrm{Cu}$, but it is not possible to observe the presence of boron crystals and the sample B5 shows the presence of the $\mathrm{Cl}$ and $\mathrm{S}$. This shows that the Boron did not crystallize and therefore not formed crystallites and then one can say that in the sample was analyzed nanoparticles are completely insulated in the glass matrix. In these spectra of the B5 sample as the sample B3 was also possible to observe two peaks related to silver nanoparticles. Analysis of the TEM micrographs showed that the thermally treated borosilicate glass samples contain nanoparticles due to the result of diffusion processes, reduction, aggregation and crystal growth, where the size of the nanoparticles increases with the heat treatment (time and temperature).

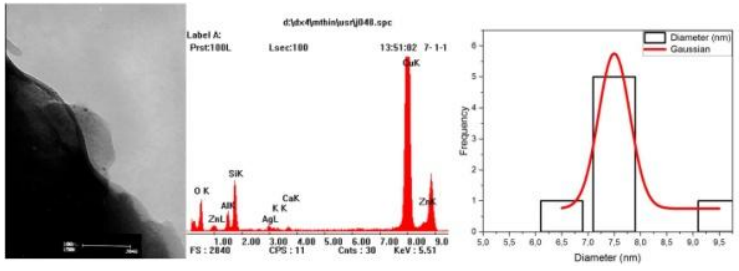

Figure 4: (a) Results of TEM micrographs and (b) EDX of borosilicate glass sample doped with silver nitrate and heat treated at $300{ }^{\circ} \mathrm{C}$ for one hour (B3). Showing distinct regions: Sample (B) B3. (c) Corresponding size distribution with Gaussian curve fit.

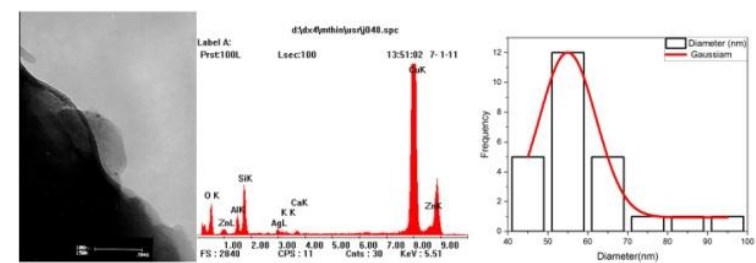

Figure 5: (a) Results of TEM micrographs and (b) EDX of borosilicate glass sample doped with silver nitrate and heat treated at $300{ }^{\circ} \mathrm{C}$ for one hour. Showing the region (C) Sample B3. (c) Corresponding size distribution with Gaussian curve fit.

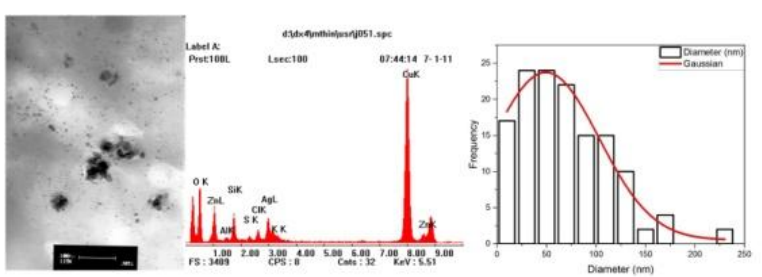

Figure 6: a) Results of TEM micrographs and (b) EDX of borosilicate glass sample doped with silver nitrate and thermally treated at $400{ }^{\circ} \mathrm{C}$ for one hour (B5). Showing the region (A) Sample B5. (c) Corresponding size distribution with Gaussian curve fit.

\section{Conclusion}

From the differential thermal analysis (DTA) it was not possible to obtain good thermal stability, but in 
return the Hruby parameter was found to be satisfactory, indicating that the glass produced did not show any crystallization, which is a very important factor due to the applicability of pure glass materials for technological applications. For borosilicate glass samples doped with silver nitrate undergone different heat treatments in the range of $2000 \mathrm{C}$ to $500 \mathrm{OC}$ for one hour, it is possible to see that micrographs confirms the presence of silver particles or their aggregates, that had the same spherical shape with average diameters ranging from $10 \mathrm{~nm}$ to $100 \mathrm{~nm}$, since their absorption bands were included in the range between $400 \mathrm{~nm}$ and $600 \mathrm{~nm}$. And can also verify that results from the diffusion processes, reduction, aggregation and crystal growth. The size of the nanoparticles increased linearly with the increase of annealing temperature. Through the EDX spectra obtained by the technique of transmission electron microscopy was not observed the presence of the boron crystal in any of them, then it can be said that in the sample analyzed the nanoparticles were fully isolated in the glass matrix. One can verify the presence of the following chemical elements: Ag, Al, $\mathrm{Zn}, \mathrm{Si}, \mathrm{Ca}, \mathrm{O}, \mathrm{S}, \mathrm{Cl}$, and $\mathrm{Cu}$. No Na peaks found in the EDX spectrum.

\section{Acknowledgment}

The authors are grateful to the Brazilian Agencies: FAPEMIG (Projects: APQ-01615-12: Title: Sustainable development: Use of glass fibers in the production of composites used by civil construction. APQ-01586-10: Synthesis and characterization of special glasses for photonic application. APQ- 0146710: Molecular photophysics: an atomistic approach), FAPESP, FINEP, CAPES, CNPq. We also thank the Dr. Pedro Kunihiko Kiyohara from Laboratory of Electronic Microscopy -IFUSP for help with microscopy.

\section{References}

[1] P. N. Prasad, Nanophotonics, John Wiley \& Sons, 2004.

[2] T. Tokizaki, A. Nakamura, S. Kaneko, K. Uchida, S. Omi, H. Tanji, Y. Asahara, Subpicosecond time response of third-order optical nonlinearity of small copper particles in glass, Applied physics letters 65 (8) (1994) 941-943.

[3] J. Giehl, W. Pontuschka, L. Barbosa, E. Chillcce, Z. Da Costa, S. Alves, Thermal precipitation of silver nanoparticles and thermoluminescence in tellurite glasses, Optical Materials 33 (12) (2011) 1884-1891.

[4] A. Carmo, M. Bell, Z. Da Costa, V. Anjos, L. Barbosa, E. Chillcce, J. Giehl, W. Pontuschka, Optical and spectroscopic properties of soda lime alumino-silicate glasses doped with erbium and silver, Optical Materials 33 (12) (2011) 1995-1998.

[5] W. Pontuschka, J. Giehl, A. Miranda, Z. Da Costa, A. Alencar, Effect of the Al 2 O 3 addition on the formation of silver nanoparticles in heat treated soda-lime silicate glasses, Journal of Non-Crystalline Solids 453 (2016) 74-83.

[6] J. Almeida, L. De Boni, W. Avansi, C. Ribeiro, E. Longo, A. C. Hernandes, C. R. Mendonca, Generation of copper nanoparticles induced by fs-laser irradiation in borosilicate glass, Optics express 20 (14) (2012) 15106-15113.

[7] S. Qu, Y. Gao, X. Jiang, H. Zeng, Y. Song, J. Qiu, C. Zhu, K. Hirao, Nonlinear absorption and optical limiting in gold-precipitated glasses induced by a femtosecond laser, Optics communications 224 (4-6) (2003) 321-327.

[8] Y. Teng, B. Qian, N. Jiang, Y. Liu, F. Luo, S. Ye, J. Zhou, B. Zhu, H. Zeng, J. Qiu, Light and heat driven precipitation of copper nanoparticles inside $\mathrm{Cu} 2+$-doped borate glasses, Chemical Physics Letters 485 (1-3) (2010) 91-94.

[9] J. Shin, K. Jang, K.-S. Lim, I.-B. Sohn, Y.-C. Noh, J. Lee, Formation and control of au and ag nanoparticles inside borate glasses using femtosecond laser and heat treatment, Applied Physics A 93 (4) (2008) 923-927.

[10] B. G. Parkinson, Influence of composition on structure and caesium volatilisation from glasses for hlw confinement, Ph.D. thesis, University of Warwick (2007).

[11] Y. Teng, B. Qian, N. Jiang, Y. Liu, F. Luo, S. Ye, J. Zhou, B. Zhu, H. Zeng, and J. Qiu. Light and heat driven precipitation of copper nanoparticles inside $\mathrm{Cu}(2+)$-doped borate glasses. Chem. Phys. Lett. 2010; 485(1-3), 91-94.

[12] Y. Teng, J. Zhou, F. Luo, G. Lin, and J. Qiu. Controllable space selective precipitation of copper nanoparticles in borosilicate glasses using ultrafast laser irradiation. J. Non Cryst. Solids. 2011; 57(11-13); 2380-2383.

[13] J. R. Qiu, M. Shirai, T. Nakaya, J. H. Si, X. W. Jiang, C. S. Zhu, and K. Hirao. Space-selective precipitation of metal nanoparticles inside glasses. Appl. Phys. Lett. 2002; 81(16), 3040-3042.

[14] J. Shin, K. Jang, K.-S. Lim, I.-B. Sohn, Y.-C. Noh, and J. Lee, Formation and control of $\mathrm{Au}$ and $\mathrm{Ag}$ nanoparticles inside borate glasses using femtosecond laser and heat treatment. Appl. Phys. A: Mater. Sci. Process. 2008; 93, 923-927.

[15] K. Uchida, S. Kaneko, S. Omi, C. Hata, H. Tanji, Y. Asahara, A. J. Ikushima, T. Tokizaki, and A. Nakamura. Optical nonlinearities of a high-concentration of small metal particles dispersed in glass: copper and silver particles. J. Opt. Soc. Am. B. 1994; 11(7), 1236-1243.

[16] SHELBY, JAMES.E, Introduction to glass science and techonolgy The Royal Society of Chemistry, Second Edition, 2005; 